\title{
Wolof Terminology: Lexical Morphology and Sociolinguistic Implications
}

\author{
Abibatou Diagne \\ Laboratoire CRTT (E.A. 4162), Lyon, France \\ E-mail: diagneabi@gmail.com
}

Received: August 2, 2020 Accepted: September 8, 2020 Published: September X, 2020

doi:10.5296/ijl.v12i5.17744

URL: https://doi.org/10.5296/ijl.v12i5.17744

\begin{abstract}
In this paper, we study the lexical morphology of Wolof and tools for terminologization. We focus on prefixes and suffixes. We will apply morphological analysis using the NooJ tool for the identification and extraction of terms from a corpus. We will also discuss the modality of corpus constitution and sources.

The lexicon and morphology of Wolof are pretexts for terminological work. Beyond the linguistic aspects, we are interested in the sociolinguistic implications of the development of terminological units in this language. This is part of the general framework of language planning which, to be effective, must be taken into account through a clear and accepted language policy. The social impact covers the fields of scientific and general culture, thus contributing to the vitality of the language, to its social consolidation and to a change in the perception of speakers towards Wolof.
\end{abstract}

Terminologie wolof: morphologie lexicale et implications sociolinguistiques

Keywords: Lexical morphology, Corpus, Wolof, Terminology, Sociolinguistics

\section{Introduction}

The paper focuses on lexical morphology of Wolof and tools for terminologization. We insist on prefixes and suffixes. We will apply morphological analysis using the NooJ tool for the identification and extraction of terms from a corpus. The modality of corpus constitution and sources will be discussed.

Wolof lexicon and morphology are pretexts for terminological work. Beyond the linguistic aspects, there are sociolinguistic implications for the development of terminological units in this language. This is part of the general framework of language planning which, to be 


\section{Ml Macrothink}

International Journal of Linguistics

ISSN 1948-5425

2020, Vol. 12, No. 5

effective, must be taken into account through a clear and accepted language policy. The social impact covers the fields of scientific and general culture, thus contributing to the vitality of the language, to its social consolidation and to a change in the perception of speakers towards Wolof.

\section{Theoretical Background}

\subsection{Lexical Morphology}

The richness of Wolof morhphology (both verbal and nominal) has been emphasized in several works, including Robert (2011), Ka (1981) and Church (1981). The most representative word formation processes in Wolof are derivation and compounding, with lexical borrowing being among the less productive ones. Changes in these lexical processes concern both the verbal structure (tense-aspect-mood, henceforth TAM) and the nominal structure, particularly with regard to gender and number. We mention here ( $\$ 1.1$ to $\S 1.3)$ some principles and rules of Wolof lexical morphology, including derivation, compounding and lexical borrowing.

\subsection{Derivation}

The structure of the derived word in Wolof consists of a stem and a radical that can be broken down into smaller units. Following N'diaye (2004: 63), lexical rules of word formation can be formulated as shown below:

1) $X Y$

This rule in which $\mathrm{X}$ and $\mathrm{Y}$ constitute lexical categories, can be used since it allows us to draw up a good part of derivation forms in Wolof. Examples (2-4) show cases of suffixation, while examples (6-7) illustrate prefixation in Wolof.
2) $\mathrm{Xn}$
$[[X n+$ Affv $]] Y v$
3) $\mathrm{Xv}$
$[[\mathrm{Xv}+\mathrm{Affv}]] \mathrm{Yv}$
Fitna
Fitna-al
Bëgg
Bëgg-al

Torment, to torment

to love

Make sm love sg

4) $\mathrm{Xv}$

$[[\mathrm{Xv}+\mathrm{Affn}]] \mathrm{Yn}$

5) $\mathrm{Xa}$

$[[\mathrm{Xa}+\mathrm{X}]] \mathrm{Yn}$

Nekk Nekk-in

Gàtt

Gàtt-aay

To be, Way of being

Short

Shortness

We note that these rules apply to suffix derivations. In Wolof, there are fewer prefixes (about a dozen) than suffixes.
6) Affn
$[[\mathrm{Affn}+\mathrm{Xn}]] \mathrm{Yn}$
7) Affn
$[[\mathrm{Affn}+\mathrm{Xv}]] \mathrm{Yn}$
Aji
Aji-kàttan
Way
Way-dencante
The one who
Almighty
The one who
Couple 


\section{IIMacrothink}

International Journal of Linguistics

ISSN 1948-5425

2020, Vol. 12, No. 5

We note that these rules apply to suffix derivations. In Wolof, there are fewer prefixes (about a dozen) than suffixes.
6) Affn
$[[$ Affn + Xn] $]$ Yn
7) Affn
$[[\operatorname{Affn}+\mathrm{Xv}]]$ Yn
Aji
Aji-kàttan
Way
Way-dencante
The one who
Almighty
The one who
Couple

In the different processes, the affixes constitute the morphological head which determines the grammatical category of the derived word.

\subsection{Compounding}

Compounds are made up of at least two lexical items (a head and its dependent). The head may be inflected in the genitive using functional morphemes ( $-u$ for singular or $-i$ for plural). This is a training rule for the least classic. On the basis of the parts of speech (POS), there are four types of compounds: (a) nominal compounds, (b) verbal compounds, (c) adjective compounding (Note 1) and (d) adverbial compounding.

The nominal compounds are:

(a1) NN (jangoro-kajoor, syphilis)

(a2) NV (xar-kanam, face),

(a3) $\mathrm{N}+$ Morph $\mathrm{N}$ (doomu jangoro, microbe).

Other nominal compounds may not include any nominal element:

(a4) VAdj (wësin-wees, delivered),

(a5) VV (dox-daje, meeting place).

Verbal compounds are of VN type:

(b1) (door-waar, to work).

Adjectival compounds include an adjective and a noun:

(c1) Adj N (rëy-xol, generous).

The adverbial compounds generally include a conjunction or preposition and its form may vary:

(d1) Prep N Det (ci saa si, at the moment).

Most compound words have an orthographic hyphen. This is an influence of the French spelling, even if on a prosodic plane it is possible to perceive compounds that does not reveal a process of compounding (wax dëgg [litt, say true], really!) 


\subsection{Lexical Borrowing}

Lexical borrowing is the transmission from one language to another of a label in the view of naming a concept (Grant, 2015). Borrowing is certainly the most visible and the most disparaged case of change on languages. It is considered, in terms of neology, as the poorest lexical creation process. Many textbooks, Hock \& Joseph (1996), Thomason (2001), show that "core vocabulary" is very rarely (or never) borrowed. The term 'lexical borrowing', in a general sense, includes all types of transfer from one language to another. Thomason \& Kaufman (1988), in a restrictive approach, define it as "the incorporation of foreign elements into the speakers' native language". Following Thomason \& Kaufman, I use it in this paper to refer to a linguistic process consisting in taking a foreign linguistic element and integrating it into a given language. From a formal point of view, lexical borrowing can be of four types : (a) total, (b) adapted, (c) modified and (d) mixed.

Total lexical borrowing includes all loanwords that enter the language without any modification or adaptation (e.g. Sida, AIDS). It should be noted that total lexical borrowing is frequently done by bilinguals, however, from a linguistic view, when the item becomes a loanword, it might be subject to modification or adaptation.

Adapted borrowing is often a morphophonological process that involves finding phonemes and substitution morphemes (kamisol, camisole). Modified lexical borrowing is a borrowed lexicon that is not necessarily motivated by phonological or linguistic reasons (lopitaal, hospital). The mixed lexical borrowing combines adaptation and modification (boyetu bopp, cranial box).

\section{Corpus}

Initially, we wanted to only use a Wolof monolingual corpus. However, as this corpus was quite small, we translated some specialized terms starting from the Greek and Latin formants into French. The monolingual corpus consists of booklets with around two thousand term occurrences. The themes developed in these booklets are related to maternal and child health.

The translated corpus consists of Greek and Latin affixes and formants found in French medical terminology. There are also terms in form of collocations.

Translation of the corpus was done by the author (X, 2018).

Moreover, the Wolof-French dictionary (Diouf, 2003) has been used as a reference frame, as it currently remains the largest-supplied Wolof lexicographic source.

\section{Morpho-Semantic of Wolof Medical Terms}

In Diagne (2018), we found some salient semantic elements from our medical corpus which can be grouped under five notions: 'abnormally excessive functioning', 'difficult functioning', 'degradation', 'inadequate functioning / state' and 'abnormal decrease'.

The affix -ukaay and its variant -uwaay convey the notion of 'means' or 'tool', but the may also have a locative meaning: 


\section{Mll Macrothink}

8) njur-ukaay: uterus

9) saw-ukaay: urinary system

10) paj-ukaay: health facility

11) ceegat-ukaay: laboratory

12) war-uwaay: vein, artery

These examples from our corpus, follow the derivation rules mentioned above (from 1 to 7 ). We must add the consonant alternation, a morphophonological rule that builds deverbals. The principle is simple, since it is a question of replacing the initial phoneme of the verb with another "stronger" phoneme.

We have these cases when the occlusives $(b, d, j, g)$ are prenasalized (Example 8, jur which means "to give birth" is prenasalized in order to have the meaning of 'place of conception' or 'uterus').

The other cases of consonantal alternation concern the fricatives $(f, s)$ and the constrictive $(w)$ which become occlusives.

Examples 10 and 11 have fricatives ( $f$ and $s$, respectively) at the initial of their verbal base (faj, seeg).

The affixes -adi and -aji have a bit more complex morphosyntactic behavior.

The -adi affix includes the meaning of 'not right'. It introduces a concept of inadequate state or functions as defective when combined with a basic lexeme. In our corpus, we note that -adi often occurs in the context of several sequences that correspond to collocations in French.

13) jekkadi bëñ: dental anomaly

14) jagadi wextan: biliary dysfunction

15) xol wu jagadi: cardiac malformation

16) xel mu weradi: psychic anomaly

17) ngelabon bu jagadi: fetal malformation

As for the affix -aji, in Diagne (2018), we consider it as an expansive substantive that introduces verb phrases, it requires a determination.

\section{Terminology Activities: Successful Examples}

Terminology was born and mainly shaped in three areas: the Vienna School, the Prague School and the Soviet School.

In Vienna, Eugène Wüster lays the foundations for the General Theory of Terminology (TGT) by defending in 1931 his thesis which deals with the theme of international standardization of the technical language. The Austrian work details the characteristics of terminology which is 
considered as a communication tool which reduces the various pitfalls that users of a given technical language may face. Wüster's terminology is "purely methodological and normative" (Rondeau, 1984). He was keen to harmonize terms and concepts in specific areas. Wüster's interest in language was secondary; he was more concerned with efficiency and precision. The ISO organization was largely inspired by Wüster's works. According to Felber (1987) "he is responsible for almost all projects related to Recommendations of the Standard. "

Terminology under the Prague school has a philosophical component in addition to marrying Saussurian structuralism. Indeed, it insists on the relationship between language, thought and reality. It put the common language at the heart of the studies carried out. The common language is approached from a functional angle, a communication tool used in different areas of life.

In a linguistic approach, the Soviet school, under the leadership of Lotte, initiated work on the theoretical basis of terminology. It must also be said that this school was particularly influenced by Wüster. The elements developed revolve around the uniqueness of the term, the impact of the change of meaning on the creation of terms as well as their structure among other elements.

Over the decades, terminology has developed around the world, particularly in European countries. It becomes a real tool for asserting identity in Quebec and in Catalonia, but also a necessity for linguistic planning and standardization.

\section{French in Quebec}

In Quebec, we find the most successful landscaping work, mainly regarding the methodological aspects. The country is a pioneer in the field of terminology planning. The term "linguistic development" was proposed in the 1970s by Jean-Claude Corbeil, a Quebec linguist, as part of a law dealing with Quebec language policy related to several social fields.

Quebec proposed a methodological reflection on terminology work in the 1970s, instead of being interested in theoretical considerations. This is partly explained by a practical approach, objective of which is to respond to specific problems. The choice of such an approach makes Quebec a place of strong terminological dynamism, both from a translational (designing and supplying terminological databases serving as support for translators) and sociolinguistic point of view (promoting and defending the use of French as a means of communication and work).

The methodological approach of Quebec work has a systematizing dimension, one of the most visible aspects of which is the interest given to neology. This is due to the desire to systematically replace the multitude of borrowings, mostly Anglicisms, by French terms. The great English scientific culture has had an influence on the most widely used languages of international communication. Dubuc (1997) is one of the most important authors that have worked in the practical and theoretical dimensions of terminology in Quebec. 
Terminology practice for the use of French in Quebec has included all socio-professional sectors of the state. The main idea behind francization was to replace all anglicisms in an essentially anglophone environment. So there has been an institutionalization of terminology.

\section{Catalan}

Catalan terminology activity is based on considerations linked to nationalism, even if Cabré (1989) also notes the actions of a civil society endowed with a high cultural level and a strong industrialization. The sensitivity of the linguistic question in Spain, to be placed in the historical context of the Franco dictatorship, means that the development work has been very tightly regulated from a legal point of view. Between 1983 and 2010, no less than thirteen legal texts relating to language laws were published.

Maria Teresa Cabré's works were of great theoretical contribution, especially for the term as an object of study of terminology. She developed the " theory of doors" which offers a perspective in four points. The first one concerns the interdisciplinary nature of terminology which includes cognitive, linguistic, semiotic and communicative aspects. She insisted, as a second point, on the interest of developing a theory of terms instead of a theory of terminology. The third point gives the characteristics of the terminological units which are linguistic units appearing in a natural language. The fourth point makes a comparison between terminological units and non-specialized lexical units. According to Cabré, these units have some similarities and dissimilarities which boil down to the pragmatics and the mode of signification.

Cabré (1999, 2000a, 2000b), offers a communicative theory of terminology. An open door leads to a certain discourse which reveals communication needs. That is the reason why, we must be interested in terminology not from its designation role, but as a linguistic system. The linguistic system is what allows exchange through the actualization that speakers make of it. This update places terminology at a discursive level which determines the status of a term.

Beyond the theoretical contribution, the Catalan terminology works, due to the political will displayed by the authorities of the Autonomy, constitute now a reference in terms of successful linguistic planning. This translates into effective use in the fields of education, administration, promotion of Catalan culture, all of this being supervised by institutions in charge of standardization works.

\section{Research Methods}

\subsection{Nooj Morphological Analysis}

The morphological rules give us the possibility to automatically generate the most representative terms based on certain affixes. Using NooJ we can create morphological and syntactic graphs that recognize sequences of letters and word sequences, respectively. We describe these rules by using a rule or graphic editor. Diallo, Corenthin, Lishou (2012) have proposed some rules of Wolof grammar constructions. They propose to focus on affixation, inflational grammar of nouns and verbal derivation. The work is however not exhaustive 


\section{Macrothink}

International Journal of Linguistics

ISSN 1948-5425 2020, Vol. 12, No. 5

since there is a need to improve the names of entities in Wolof, but also to develop a spell checker.

The following rules of affixation govern our grammar:

Suffixation rule "suf"

suf $=$ suf $/ \mathrm{V}$

$\operatorname{suf}=\operatorname{suf} / \mathrm{N}$

Prefix rule

prefixe $=\langle\mathrm{LW}>$ prefixe $-/ \mathrm{N}$

prefixe $=<\mathrm{LW}>$ prefixe $/ \mathrm{V}$

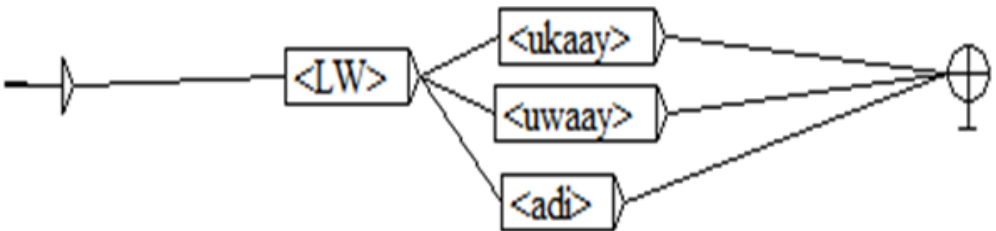

Figure 1. Derivational grammar of -adi, -ukaay, -uwaay

This grammar allows us to identify, lexemes and to extract them.

Moreover, the consonant alternation, calls another rule that takes into account the permutations of phonemes.

Morphological rule of consonantal alternation

Alternance $=\langle\mathrm{LW}>$ alter $\langle>/ \mathrm{N}$

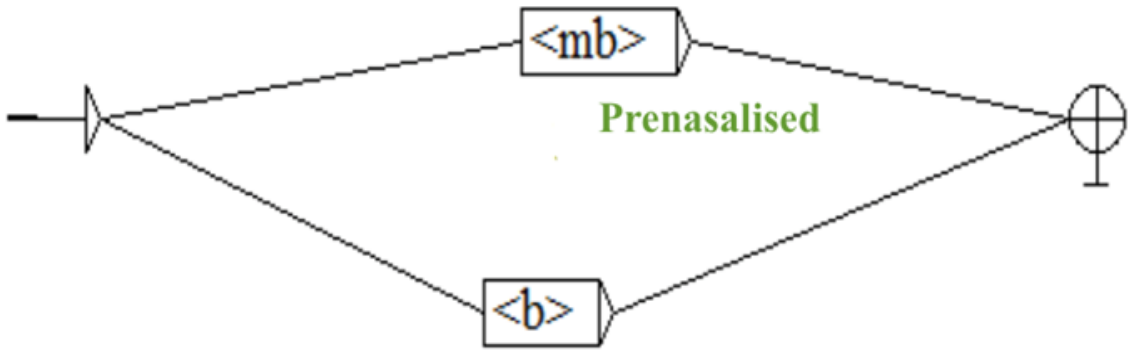

occlusive

Figure 2a. Prenasalized grammar of an occlusive 


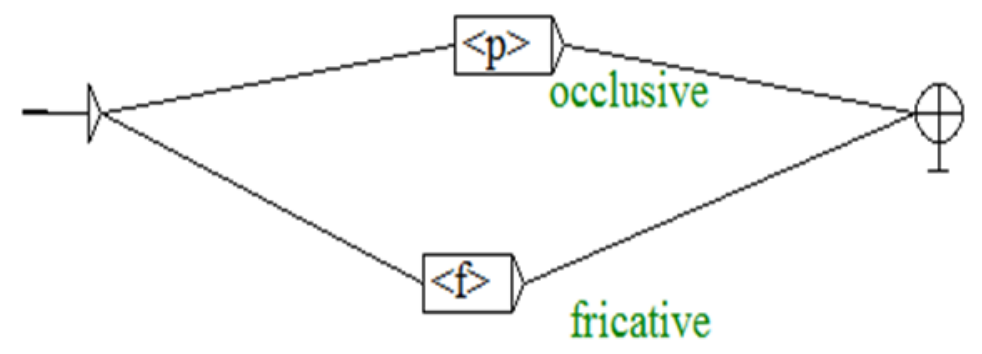

Figure $2 b$. Fricative grammar from (f) to (p)

To these rules which make it possible to find terms, it is possible to go to a grammar which would find sequences with up to three or four elements which constitute terminological units in Wolof.

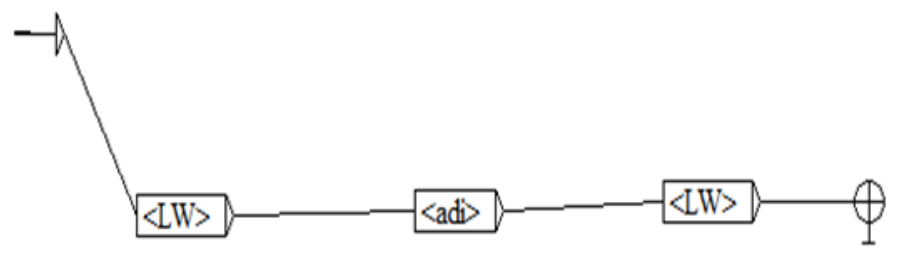

Figure 3a. Grammar of sequences, of Wolof terminological units (affix -adi)

This rule allows the identification of examples of type $\S 13$ and 14.

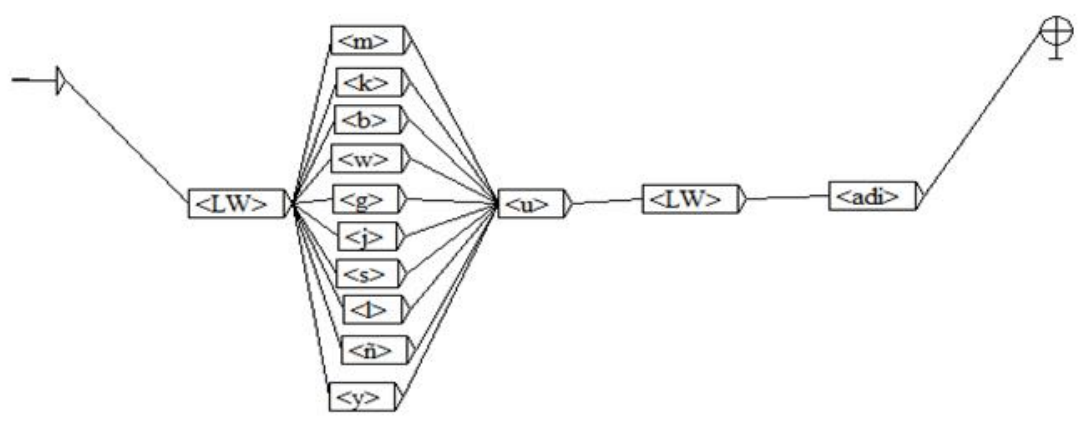

Figure 3b. Grammar to find sequences (-adi)

Figure 3 gives the sequences found in $(\S 15,16,17)$. The various Wolof classes are integrated to take into account all the lexemes nominals that would be in the corpus. 
In a descriptive approach, Pozdniakov and Robert (2015) give the functional principles of the Wolof nominal class system, following previous studies (Delafosse 1927; Senghor 1943; Sauvageot 1965; Samb 1983; Ndiaye 1995). They emphasize the simplification of this system, even if "the use of spatial deictics has favored the constitution of a rich paradigm of determinants" (Pozdniakov and Robert, 2015).

The NooJ analytical tool shows some limitations when it comes to analyze complex issues in the Wolof morphological system. This is particularly true, as ambiguity remains a perversive phenomenon in Natural Language Processing (NLP).

With respect to this, Dione $(2014,2019)$ has proposed models based on the Lexical Functional Grammar (LFG) framework that seek to analyze both theoretical and practical issues of ambiguity in Wolof. Dione (2014) proposed a syntactic analysis system for Wolof capable of removing ambiguity. The system identified various types of ambiguities, including morpholexical, syntactic, and referential ambiguity. Syntactic ambiguity can produce a structural ambiguity that combines both lexical and syntactic ambiguity:

18) Xale b-i moom doon ree.

child cl-DFP adv.TOP IPF.PST laugh

child cl-Rel own COP laugh child cl-DFP own IPF.PST laugh

"As for the child, (s)he was laughing." "The child who owns (something) becomes a laugh."

"The child owns (something) and was laughing." (Dione, 2014)

In the search for terminological units on corpus, it appears that the use of a syntactic analysis system is operative for a better extraction. The implementation of Dione's Wolof grammar allows a morphological disambiguation of the nominal classes. Moreover, it deals with the fact that the Wolof noun class system can have different values and the noun itself 'can satisfy different class requirements'. If we take examples $(\S 15,16,17)$ and their representation in NooJ, we may have effective extraction but that do not give semantic distinction. In these examples, we just take restrictive sequences ( $\mathrm{LW}+\mathrm{CLN}+\mathrm{Relat}-\mathrm{U}+\mathrm{LW}$ ), but we also can introduce other relative individual markers different from $(-u)$, that would imply other consequences.

Torrence (2013) showed interest in the Wolof clause structure and the relative individual markers $-i$ and $-a$ when used for defined Head Nouns (HNs), imply proximity (- $i$ ) or distance (- $a$ ) relationships spatially, temporally than discursively.

However if in general language, discursive variations have a semantic impact, the constitution of terminological units requires contextualization and a one-to-one approach which tends to reduce it.

A syntactic analysis system is useful for pre-extraction or a work in general language so as to document Wolof language and identify term-candidates. 


\subsection{Terms Extraction}

The study of affixes and morphological rules of Wolof terminology would normally require a larger corpus. There are a number of constraints, but we think that borrowing would come out more forcefully on a larger part of work. It should also be emphasized that the absence of written Wolof sources in the specialized fields calls for a constitution work that is oriented towards the spoken word. In the medical field, this can be done through physician-patient dialogues.

The oral study, which we have rarely mentioned, requires a praxematic approach that takes the opposite of the lexical study. We have found some terms in an oral corpus, but we have not emphasized the discursive dimension. We note in this corpus the expansive characteristic of the equivalent terminological units, which take up the salient features of the term concept (see examples 8 to 17). Beyond the forms that terminological units can take, the question arises for the semantic scope and socioterminological side of minority languages.

We consider that the context of constitution of Wolof specialized oral corpus, mainly through the media channel (cf. Kébé, 2011, Ndao and Kébé 2010), reveals praxis associated with domains and their objects. From this point of view it is possible to have a different semantic approach. The analysis of these corpora calls for consideration of the language historicity and "terms as praxes", since their "use is linked to professional practices and that [their] use is not without stakes "(Gaudin, 2003).

\section{Finding and Discussions}

\subsection{Terminology Building for Language Planning}

\subsubsection{Means and Obstacles}

\section{Linguistic means}

There are several methods for developing the terminology of a language that can be found in three categories: the use of existing resources, the modification of existing resources and the creation of new linguistic entities (Sager, 1990).

The use of existing resources makes it possible to update and extend the meaning of a word or a term in order to adapt it to the concept developed.

Existing resources modification goes in the direction of existing resources use. Some formal changes have to be carried out within the framework of lexical morphology.

The creation of new linguistic entities can take the form of borrowings or completely new units. Terms, unlike words, are not arbitrary. It is possible to formally trace its components or to detect the motivation of its choice. Computer terminology is an example of transparent and motivated units.

\section{Political means}

From the planning perspective, terminology includes a strong political significance. Linguistic planning constitutes work on an intangible heritage shared by one or more 
communities. Intervention on a language as a whole therefore follows a political will. Beyond the recognition of official languages status, the promotion of national languages goes through their development and their openness towards scientific and technical knowledge.

The languages used on an international scale, due to a strong influence of anglicisms, have been "adapted" hence the establishment of language policies (for example in Catalonia), or of official organization (the DGFLF, in France). Terminology is therefore first of all a practical discipline, exercised in a framework that aims to be reforming and / or normalizing.

\section{Obstacles}

The implementation of a terminology enrichment work involves obstacles on several levels.

Documentation is the first challenge faced by terminologists (and translators) in their practice of terminology activity. It is a research stage during which the understanding and the situation in the context of the terminological unit created or to be created are made. The documentary approach can be monolingual or multilingual, the objective being only to manage to grasp the specialized concepts. But the existence of important monolingual documents predisposes to easier terminology. The absence of technical, scientific or general writings necessarily has a consequence on the greater or lesser profusion of terms.

In addition, two concepts constitute both means and obstacles: linguistic planning and standardization. They make it possible to determine rules for terminology and harmonization of units. However, for a successful linguistic adjustment and standardization, it is necessary that they emanate from recognized authorities.

With regard to standardization, Rondeau (1983) identifies ten prerequisites consecutive to a job or to a policy of terminology development or enrichment. Beyond institutionalized care, these fundamentals concern:

- $\quad$ the need to work on the specialized language and that this work is not an end in itself but a clearly defined objective of improving communication;

- $\quad$ the sociolinguistic dimension (which we will discuss);

- $\quad$ psycholinguistic values related to the aesthetics, motivation and habits of speakers ;

- the stable nature of standardization to be an everyday reference for users of the language;

- the need for coordination according to the level of application (national, international);

- collaborative work between terminologists and subject specialists;

- the use of recognized methods as well as the productions (files) which result therefrom;

- finally the communicative scope for a wide dissemination of standards.

Meeting these conditions to develop terminology units would be an open door to the development of terminologies, however making it much more difficult. 


\section{Ml Macrothink}

International Journal of Linguistics

ISSN 1948-5425

2020, Vol. 12, No. 5

Obstacles to terminology work in the Wolof language are linked to language, not as a system, but to its status. Wolof is a vernacular, mainly for oral use. It is not a written communication tool in the most common language practices. Its sociolinguistic context of use remains confined. The absence of abundant literature is a reality and literary works in the Senegalese context are few, particularly in specialized fields. It is only within the framework of academic research that it is possible to find interesting and large-scale works.

The major obstacle is undoubtedly the scope that terminology work can have, the interest it can arouse among speakers or learners. The stake of such work determines the decision to put into practice a terminological planning.

\subsubsection{Wolof Specific Considerations}

\section{Linguistic work}

The required work for the terminological development of Wolof can take several linguistic forms. Borrowing, creating new terms are some examples, but it appears that the use of paraphrase offers satisfactory results.

The paraphrase seeks an accuracy apprehended through the situational sense or literal sense. It is also necessary to contextualize semantic neutralization, which amounts to erasing the distinctions for a reduced or centered semantic diversity. This makes it possible to produce sequences close, from a synonymic point of view, to the paraphrased utterance.

Paraphrase is presented as a means of establishing language-to-language equivalences (translation, interlinguistic approach to paraphrase). It is also an exercise in reformulation which starts from a meaning, from information to give a formal representation equivalent to that meaning (intralinguistic approach). The equivalence is part of paraphrase, since the semantic identity, that is to say perfect synonymy, between an utterance and its paraphrase, cannot be reached. The intralinguistic paraphrase is an exercise that explains a new (i.e. foreign) or unclear notion. From this point of view, it can be useful for the definition of terms or their presentation in a terminology sheet.

The interlinguistic paraphrase essentially remains an exercise in translating semantic, informational content conveyed by a term. Indeed, literal interpretation cannot be envisaged because of linguistic constraints and sometimes unsatisfactory results. It is also a widely used technique in popularization since it involves a work of reformulation on the terms. These terms may have no equivalents formally attested as such in Wolof.

The paraphrases are based on a language practice of reformulation which highlights a "communicative sense". This structures the statement according to the informative content to be communicated or highlighted. This gives rise, in terms of Wolof syntax, to a form of synthetic focusing $(\mathrm{X}, 2018)$.

\section{Political framework}

Linguistic planning defines the objectives of terminology in terms of description, modernization, and implementation of terms. Depending on the language typology, the 
objectives may turn out to be a need to demonstrate that languages can express modernity (especially for languages with a strong oral tradition). Even if it appears that linguistic planning must be done within a determined institutional framework underpinned by a predefined linguistic policy, the reality is quite different. Language planning is a long, tedious job, with sometimes inconclusive results. Even with the adoption of a rigorous and structured approach, there is no guarantee that the implementation of terms will be effective and that the social communities take ownership of the proposed work. In fact, language policies "formalize in social or administrative practices" (Rousseau, 2005).

\subsection{Sociolinguistic Implications}

We have seen that language can be both a mean and an obstacle to knowledge development and transfer. By meeting certain conditions, obstacles can be overcome. The greatest obstacle to the instrumentalization of the language in the terminological domain remains the written resources. Documented languages in writing have lot of advantages. These writings can be linked to literature but also to education or even have an institutionalized presence. The reason for such a pre-requisite is that languages for specific purposes have developed around the written texts, by the stable nature of this medium. It therefore appears that terminological development in a language mainly for oral use requires upstream work with numerous sociolinguistic consequences.

\subsubsection{Building of Information and Scientific Culture}

\section{General and scientific culture}

Terminology is the most visible element of technical languages. These one are not commonly used in any language community, since they are referred as the languages of experts in a given field. Terminology presents itself as a tool for scientific instrumentalization of the language when it is its most changing and modular aspect that is enriched. The term is only the physical materialization of the most interesting aspect of the construction of information: the concept.

Conceptualization is an essential step in cognitive development and involves elements such as the percept. Each of the stages of construction of information requires research or excavation either in the lexical stock or in day-to-day life or in the heritage of the language.

When "computer" first appeared, it was a "term" that seasoned computer scientists. Today, it has become a word that has entered into common language. This passage from term to word is a process of de-terminologization. This process, even if it takes us out of the fields of speciality, promotes the development of a general culture. Even though there may have changes in the semantic aspects of the word Meyer, I. and K. Mackintosh. (2000), the essence is not lost sometimes. For example, "computer" keeps on being related to informatics, information technology as a specialized field. We also noted that linguistic terminological processes can be inspired by existing lexical stock to update or extend the meaning of a word or term. 
In terms of scientific culture, terminology is a means of instrumentation. Any profession, any area of speciality has its own elements of language. Terminology is the basis of these language elements. The development of terminology units in a poorly endowed language therefore contributes to its cognitive densification.

'Approaching the study of terminology from its cognitive dimension requires an understanding of the structure of knowledge in order to obtain as complete and coherent a picture of the nature, behaviour and interaction of concepts and their associated terms as possible' (Sager, 1990).

From a cognitive approach, terminological work on Wolof will connect conceptual content with their referents, which designate realities that are taking up more and more space in the Wolophone area.

Furthermore, studying abstractions such as concepts, calls for knowledge structuring and classification exercise which require a work of definition specifying and fixing the meaning of terminological units. The concepts constitute 'discrete entities of knowledge structure'. The terminological unit as linguistic materialization of these discrete entities takes place in a social space which reappropriates it as well as all its meaning. Thus, medical, computer, scientific, etc. terms, when translated, raise questions about their ecosystem, their context of expression.

\section{Language vitality}

The concept of vitality, in language, translates a certain form of dynamism, an ability of the language to continue its life or its survival according to its importance. Ugwu (2019) underlines the fact that education, politics and media, are three key sectors that could greatly increase language vitality. Concretely, vitality consists in a degree of transmission from one generation to another. It takes on a strong cultural dimension when the transmission of a language is concomitant with the transmission of a good cultural part. It is first in the family circle that the foundations of vitality are generally built.

In UNESCO (2003) we note other parameters such as the number of speakers and two other parameters directly related to terminology work: trends in existing language domains, response to new domains and media and materials for language education and literacy.

\subsubsection{Social Consolidation}

Terminology development does not only involve scientific or technical processes, but also a social one (as it takes place in a social environment).

'Special language has its own evolution and is committed to social and linguistic constraints that differ from those of common languages. Major social implications are: processes of identification with the scientific community, acculturation, delimitation of a (new) science, budgets, personnel, prestige, recognition.' (Hermans, 1991).

Terminology practice, in a search for efficiency, cannot therefore be the result of socially non-located work. It involves a collaborative approach between the scientific community and 
terminologists. Depending on the language and the cultural context, it goes without saying that the terminology needs and the articulation of the works differ. All the interests will still be to meet possible social or expressed needs.

The lack of terminological development of a language in specified fields, especially in technology or science, leaves room for borrowings. Moseley (2010) explains the decline of languages in Africa by the fact that more and more native speakers are trying "to overcome discrimination, attain equality of opportunity and derive economic benefits for themselves and their children".

The social consolidation of terminology development calls on two somewhat different concepts but with similar objectives from a normative point of view: standardisation and 'normaison'. The first proceeds from a conscious and formalized process. The second was forged by the Rouen school and frees itself from the formal framework so that the term takes root in its social context.

The social consolidation of Wolof terminology work is situated at two levels with different constraints. Within the oral context, the terminological units will tend to lose their technical character. Indeed, spontaneously, what we note $(X, 2018)$ is that to express the specialized, the specific, or the technical fields, the speaker switches from Wolof to French or English. The existence of appropriate terms does not change much, which shows a real difficulty of the terms to be established in oral language practices. We saw earlier that written documentation in specialized fields is scarce in Wolof. This is an obstacle for for scriptural productions.

Standardization tends to provide a formal framework conducive to the development of terminologies. Standardization is in the very logic of the language, as regards spontaneity, the adequacy of the terms and their effective implementation. The absence of a dynamic production framework (used by experts 'writings, spontaneous use by speakers) constitutes a major obstacle. The social consolidation therefore goes through the proposal, the creation of a dynamic technical, scientific production framework in Wolof language.

\subsubsection{Change in Social Perception and Representation}

When a language contains voids of expressions in fields of speciality, they are filled by linguistic units (terminological units, symbols, etc.) which are foreign to it. These gaps give the impression of the inability of the language to express newness, to renew itself or to put itself on the same level as the languages of international communication. The consequence of such a state of affairs is that the vitality of the language gain less importance. This is notable for transmission from generation to generation due to the discrimination as pointed out by Moseley (2010).

Out of the thousands of languages that exist in the world, there are only six (English, French, Spanish, Arabic, Chinese, Russian) and a seventh, but to a lesser extent, German which have a status of international language with all the prestige that such a status entails. In the Senegalese social framework, French, and mainly English, enjoy this prestige. Among all the languages of the country, Wolof stands out as a vernacular, facing these two languages. 


\section{Mll Macrothink}

International Journal of Linguistics

ISSN 1948-5425

2020, Vol. 12, No. 5

The change in perception with regard to the Wolof language has a direct link with the communicative dimension of terminology, in particular the functional utility of terminological units. Many linguists have rightly insisted on the need to distinguish between language and communication, because of the numerous means of communication. However, if a mechanical connection is necessary, it is undoubtedly because language presents itself as one of the strongest vectors of communication. This consideration is all the more true in terminological practice because one of its primary goals is precisely to solve a communication problem. This problem comes down to clarity, precision and finding the most appropriate terms. From the planning perspective, it is a process of research and documentation both on a cognitive and linguistic level, which brings a plus to the language.

As we have seen, the perception of Wolof as a language remains confined to its vernacular status. The widening of its expressive power makes it a language capable of evolving in the direction of the changes that occur in a specialized context.

\section{Conclusion}

This study has discussed some of the relevant aspects of the Wolof morphological system, particularly morphological rules in Wolof terminology practice were emphasized. Even if the analysis concerns a relatively narrow field and a small corpus, we note all the density of the Wolof morphological system.

The basic lexical structure favors a learning methodology and allows an understanding of the Wolof language structure. In Wolof, we have different possibilities of terminology enrichment. To support our assumption on the specialized nature of these affixes, a comparison between written and oral corpora is necessary. This seems to show that, with the use of words containing these specialized affixes, non-specialist speakers will have a clear preference for an expansive syntax. The concept of expansion itself, which serves to clarify the statement, has been addressed in the author previous studies (Diagne: 2015a, 2015b, 2018). While postulating sensible variations of meaning, it is possible to define the scope of the notion of expansion in order to identify "semantic conditions" that are closest to equivalence. Beyond morphological considerations, we think that paraphrase studied in a morphosyntactic framework, is more likely to produce appropriate terminology units in Wolof.

In our opinion, the fields of specialization allow an approach, with respect to Wolof, as close as possible to the linguistic practices that correspond to the dynamics of this language. We must note the entire morphosyntactic and morphosemantic dimension of the terminological practice. Moreover, the morphological analysis is never completely dissociated from the phonology, which makes the morphological analysis of Wolof more complex.

Terminology building has particular impacts in language planning. In addition to those linguistic considerations, the social dimension shows a set of interesting facts. There are some successful examples of terminology planning, but all of them have been conveyed in a clearly defined political framework. Terminologies in Wolof is a way to improve its documentation and thus limiting the number of terms borrowed to foreign languages. The 


\section{Macrothink}

International Journal of Linguistics

ISSN $1948-5425$

2020, Vol. 12, No. 5

vitality of a language is mainly measured by the level of transfer from one generation to another. Most speakers of the languages used in Africa are less and less transferring to other generations to avoid discrimination. Indeed, these languages do not promise socio-professional recognition. Terminology practice to be effective must necessarily be part of an institutionalized framework, since sporadic or private works very quickly fall into oblivion. Institutionalization calls for political interventionism, with all the positive connotations behind the expression.

A successful social consolidation of Wolof terminologies undoubtedly requires a linguistic development project fed by the various researches conducted in sociolinguistics. This results in an in-depth study of the relationships that speakers have with the language and its possible specialization. In addition, there is a need for communication for this type of research. In Western countries, standardization is a stage during which, beyond the formal and semantic fixing of the terminological unit, there is a communicative will. In Wolof environment, communicative work will more effective under popularization. Of course, this can be explained by the wide use of Wolof as an oral and vernacular language, but also by the power of a medium such as radio.

\section{Convention}

CLN: Noun Class

Conj: Conjonction;

Det : Determiner;

Litt : Litterally; N : Nom;

Prep: Preposition;

V: Verb;

Adj: Adjective;

V: Verb;

Morph: Morpheme

Relat: Relative

TAM: Tense Aspect Mode

\section{References}

Abibatou, D. (2014). De quelques problèmes de traduction des adjectifs relationnels du français vers le wolof: étude sur corpus de terminologie commerciale [Relational adjectives in French: translation difficulties into Wolof]. In Traitement Automatique des Langues Africaines: Atelier TALN-RECITAL (pp. 86-98). 1er juillet 2014, Marseille, ATALA.

Abibatou, D. (2015). Langue de spécialité et études terminologiques du wolof dans le domaine médical: pour l'élaboration d'une base de données terminologique. [Specialized 
language and Wolof terminological studies in medical field: towards a terminological data base conception]. Actes du Colloque International Francophonie et Langues Nationales, 21-22.

Abibatou, D. (2018). La terminologie wolof dans une perspective de traduction et de combinatoire lexicale restreinte (Thèse de doctorat). Université de Lyon-2, Lyon.

Alioune, N. P., \& Bakry, K. A. (2010). Langues et médias au Sénégal: une expérience de normalisation langagière par les journalistes des radios privées. Enjeux et limites [Language and media in Senegal: a language standardisation experience by journalists in private radio stations: stakes and limits.]. In P. A. Ndao, \& A. B. Kébé (Eds.), Nouveaux médias et dynamiques des langues dans l'espace francophone, Glottopol (Vol. 14, pp. 17-36).

Amar, S. (1983). Initiation à la grammaire wolof. Dakar: Institut Fondamental de l'Afrique Noire.

Bakry, K. A. (2011). Le Rôle Des Radios Privées Dans Les Dynamiques Des Langues En Afrique Francophone (Sénégal) Interaction Entre Situation Sociolinguistique et Processus de Création Lexicale. Thèse de troisième cycle, Université de Rouen.

Bamba, D. C. (2014). LFG parse disambiguation for Wolof. Journal of Language Modelling, 105-165.

Bamba, D. C. (2019). Clause structure, pro-drop and control in Wolof: an LFG/XLE perspective. Nordic Journal of African Studies, 26.

Carlos, S. J. (1990). A Practical Course in Terminology Processing. Amsterdam/Philadelphia: John Benjamins.

Éric, C. (1981). Le système verbal wolof. Thèse d'État Troisième cycle, Université Cheikh Anta Diop de Dakar (UCAD).

François, G. (2003). Socioterminologie: Une Approche Sociolinguistique de La Terminologie. 1re éd, De Boeck \& Larcier: Duculot.

Grant, A. P. (2015). Lexical Borrowing. Oxford University Press.

Haby, D., Alex, C., \& Claude, L. (2012). Formalization of the Wolof with NooJ: Implementation on the Wolof dictionary. International Journal of Computational Engineering Science, 2(4), 12-28. $\quad$ Retrieved from https://www.researchgate.net/publication/292157537_Formalization_of_the_Wolof_with_No oJ_Implementation_on_the_Wolof_dictionary

Harold, T. (2013). The Clause Structure of Wolof Insights into the Left Periphery. Amsterdam; Philadelphie: John Benjamins.

Henrich, H. H., \& Brian, D. J. (1996). Language history, language change, and language relationship. Berlin: Mouton de Gruyter. 


\section{Macrothink}

International Journal of Linguistics

ISSN 1948-5425

2020, Vol. 12, No. 5

Hermans, A. (1991). Language Planning and Terminology Planning. Sociolinguistic Aspects. Meta, 36(4), 687-689.

Konstantin, P., \& Robert, S. (2015). Les classes nominales en wolof: fonctionnalités et singularités d'un système restreint [The Wolof nominal class system: functionality and particularity in a restricted system]. In D. Creissels, \& K. Pozdniakov (Eds.), Les classes nominales dans les langues atlantiques, Rüdiger Köppe Verlag, Grammatical Analyses of African Languages (pp. 567-655).

Léopold, D. J. (2003). Dictionnaire wolof-français et français-wolof. Paris: Karthala.

Maurice, D. (1927). Classes nominales en wolof [The Wolof nominal class system]. In Glückstadt, \& J-J. H. Augustin (Eds.), Festschrift Meinhof (p. 29). In M. Gabriel, \& S. Serge (Eds.), Wolof et Sérère (pp. 25-42). Dakar: Faculté des Lettres et Sciences Humaines.

Max, S., \& Tutin, A. (2005). NooJ, Un Outil TAL Pour l'enseignement Des Langues. Application Pour l'étude de La Morphologie Lexicale En FLE. [NooJ, a language processing tool for for language learning. Practical use for lexical morphology in FFL]. Alsic, 8(2).

Meyer, I., \& Mackintosh, K. (2000). When terms move into our everyday lives: An overview of de-terminologization. Terminology, 6(1), 111-138.

Moseley, C. (2010). Atlas of the World's Languages in Danger (3rd ed.). Paris: UNESCO Publishing. Retrieved from www.unesco.org/culture/en/endangeredlanguages

N'diaye, M. D. (2004). Éléments de morphologie du wolof. München: Lincom Europa.

Okwudilichukwu, U. E. (2019). Africa on the Verge of a Linguistic Genocide: The Need for Action. European Scientific Journal ESJ.

Omar, K. (1981). La dérivation et la compounding en wolof. Dakar: Centre de Linguistique Appliquée de Dakar.

Robert, D. (1997). Terminology: a practical approach. Dubuc, Robert; Kennedy, Elaine. Book. English. Published Quebec: Linguatech.

Sédar, S. L. (1983). Sur Les Relations entre Le français et les langues africaines du Sénégal [Relationships between French and African languages]. Ethiopiques, 1(2).

Serge, S. (1965). Description synchronique d'un dialecte wolof, le parler du Dyolof. Dakar: IFAN.

Silberztein, M. (2007). Formaliser les langues avec l'ordinateur [Languages modeling with computer], edited by C. de la M. Ledoux. Presses universitaires de Franche-Comté.

Stephane, R. (2011). Le wolof [The Wolof language]. In B. Emilio, J. Busuttil, \& A. Peyraube (Eds.), Dictionnaire des langues (pp. 23-30).

Teresa, C. M. (1989). La terminologie catalane: bilan des activités [Catalan terminology: an assessment of activities]. Meta, 34(3), 544-551. 


\section{Macrothink}

International Journal of Linguistics

ISSN 1948-5425 2020, Vol. 12, No. 5

Teresa, C. M. (1999). Terminology: Theory Methods and Application. Amsterdam/ Philadelphia: John Benjamins.

Teresa, C. M. (2000a). Sur la représentation mentale des concepts : bases pour une tentative de modélisation [Mental representation of concepts: bases for a modeling attempt]. In $\mathrm{H}$. Béjoint et, \& P. Thoiron (Eds.), Le sens en terminologie (pp. 20-39). Presses universitaires de Lyon.

Teresa, C. M. (2000b). Terminologie et linguistique: la théorie des portes [Terminology and linguistics: the theory of doors]. Terminologies Nouvelles, 21, 10-15.

Thomason, S. G. (2001). Language contact. Washington, D. C.: Georgetown University Press.

UNESCO. (2003). Language Vitality and Endangerment. Retrieved from http://www.unesco.org/new/fileadmin/MULTIMEDIA/HQ/CLT/pdf/Language_vitality_and_ endangerment_EN.pdfs

\section{Copyrights}

Copyright for this article is retained by the author(s), with first publication rights granted to the journal.

This is an open-access article distributed under the terms and conditions of the Creative Commons Attribution license (http://creativecommons.org/licenses/by/4.0/) 